This document is the accepted manuscript version of the following article:

Martin, M., Tritscher, T., Jurányi, Z., Heringa, M. F., Sierau, B., Weingartner, E., ... Lohmann, U. (2013). Hygroscopic properties of fresh and aged wood burning particles. Journal of Aerosol Science, 56, 15-29. https://doi.org/10.1016/j.jaerosci.2012.08.006

This manuscript version is made available under the CC-BY-NC-ND 4.0 1icense http://creativecommons.org/1icenses/by-nc-nd/4.0/

\title{
Hygroscopic properties of fresh and aged wood burning particles
}

Maria Martin ${ }^{\mathrm{a}}$, Torsten Tritscher ${ }^{\mathrm{b}, \mathrm{c}}$, Zsófia Jurányi ${ }^{\mathrm{b}, \mathrm{d}}$, Maarten F. Heringa $^{\mathrm{b}}$, Berko Sierau ${ }^{\mathrm{a}}$, Ernest Weingartner ${ }^{\mathrm{b}}$, Roberto Chirico ${ }^{\mathrm{b}, \mathrm{e}}$, Martin Gysel $^{\mathrm{b}}$, André S. H. Prévôt ${ }^{\mathrm{b}}$, Urs Baltensperger ${ }^{\mathrm{b}}$, Ulrike Lohmann ${ }^{\mathrm{a}}$

${ }^{a}$ ETH Zurich, Institute for Atmospheric and Climate Science, Universitätsstr. 16, 8092 Zurich, Switzerland

${ }^{b}$ Laboratory of Atmospheric Chemistry, Paul Scherrer Institut, 5232 Villigen, Switzerland ${ }^{c}$ now at TSI GmbH, Particle Instruments, Neuköllner Str. 4, 52068 Aachen, Germany

${ }^{d}$ now at University of Applied Sciences Northwestern Switzerland, 5210 Windisch, Switzerland

${ }^{e}$ now at Italian National Agency for New Technologies, Energy and Sustainable Economic Development (ENEA), UTAPRAD-DIM, Via E. Fermi 45, 00044 Frascati, Italy

\section{Abstract}

Biomass burning is one of the largest aerosol sources worldwide. In this study, the hygroscopic properties of fresh and aged wood burning particles were investigated under controlled laboratory conditions in several smog chamber experiments. Beech log wood was burnt in a residential log wood burner and the particles emitted during the different burning phases (starting, flaming, and smoldering) were analyzed. The particles were photochemically aged using the own volatile organic carbon emissions from the burnt wood. The hygroscopic properties of the particles at relative humidities below and above $100 \%$ were determined and compared.

The freshly emitted soot particles have a fractal-like structure. The structure collapsed in half of the experiments where soot was present for particles $\geq 100 \mathrm{~nm}$ under the presence of a high relative humidity, leading to a more compact structure. This restructuring induces an underestimation of the hygroscopicity measured with mobility diameter based methods.

The hygroscopicity parameter "apparent $\kappa$ " of fresh wood combustion particles varies between 0 and 0.39 . With aging, the hygroscopicity of the particles generally increases. This is due to the uptake of organic matter and inorganic salts, and because the particles become more oxidized.

One smoldering phase experiment was carried out, which, in contrast to the 
other experiments, showed very high apparent $\kappa$ values between 0.2 and 0.4 at the beginning of the experiment, depending on the size of the particles. These values were decreasing with time. This suggests a different composition of the particles, with a higher fraction of inorganic components initially. The results indicate that it is not possible to use only one $\kappa$ value for different burning phases and aging times of wood combustion particles in climate models.

Keywords: hygroscopic growth, CCNC, H-TDMA, secondary organic aerosol, biomass burning, aging

\section{Introduction}

Biomass burning is one of the largest sources of aerosols on a global scale (e.g. Andreae and Rosenfeld, 2008). As aerosols influence the climate, directly by absorbing and scattering light and indirectly by changing cloud properties, biomass burning particles have an impact on the climate. The main sources of these particles are open vegetation fires and domestic wood burning for heating or cooking. Biomass burning particles consist mainly of organic material (OM), black carbon (BC), and depending on the efficiency of the burning process, a varying amount of inorganic components (mainly potassium and chloride in freshly emitted particles) (Reid et al., 2005). In addition to the emitted primary organic aerosols (POA), organic aerosol mass is also formed by the photo-oxidative aging of co-emitted volatile organic compounds (VOC) and subsequent condensation as secondary organic aerosols (SOA) (Hallquist et al., 2009). Other aging processes include condensed-phase reactions, cloud-processing and oxidation of the organic aerosol (George and Abbatt, 2010). Aging processes change the hygroscopicity of biomass burning particles. Freshly emitted soot is non-hygroscopic, but it can become more hydrophilic through oxidation (see e.g. Zuberi et al., 2005; Decesari et al., 2002). The hygroscopicity of organic matter increases with oxidation in the subsaturated relative humidity regime (Jimenez et al., 2009; Duplissy et al., 2011). In the supersaturated regime, the increase in hygroscopicity differs with the oxidation level. The O:C (atomic oxygen-tocarbon) ratio of a particle is as an indicator for the aerosol oxidation level, which increases with increasing oxidation level. The increase in the CCN activity is more pronounced at higher $\mathrm{O}: \mathrm{C}$ ratios compared to lower ratios. 
Uptake of organic matter or inorganic salts on preexisting particles increases or decreases the hygroscopicity, depending on the initial hygroscopicity of the particle.

Biomass burning particles also have a strong impact on regional air quality (see e.g. Wotawa and Trainer, 2000). In Switzerland, about 12\% of the households in 2010 were heated with wood (Bundesamt für Statistik, 2010), and in the Alpine valleys wood burning is an important aerosol source (Sandradewi et al., 2008; Szidat et al., 2007). The presence of an inversion layer accumulates these particles, once emitted, in the atmosphere for several days. Also in the more populated regions of Switzerland wood burning was found to be a significant particle source (Herich et al., 2011; Lanz et al., 2010), even in the city of Zurich (Lanz et al., 2008) and also in the megacity of Paris (Favez et al., 2009). In Bejing, biomass burning contributes up to $43 \%$ to the organic carbon concentrations (Duan et al., 2004), and in a rural site in Austria, it was found to account for up to $70 \%$ of organic carbon in winter (Caseiro et al., 2009).

In order to investigate the influence of wood burning particles on climate, their hygroscopic properties need to be known, as these determine the ability of particles to take up water, grow and form cloud droplets. This determines in turn their lifetime in the atmosphere and how much solar radiation they reflect back to space. Several studies have focused on biomass burning particles from open vegetation fires (see e.g. Kaufman et al., 1998; Lee et al., 2006; Vestin et al., 2007). Only a few studies so far investigated the hygroscopic properties of biomass burning particles produced under controlled laboratory conditions, although some recent studies on freshly emitted particles from biomass burning exist. Dusek et al. (2005) conducted laboratory measurements on particles produced by burning German and Indonesian peat. They found freshly emitted particles with diameters $>200 \mathrm{~nm}$ that were non-hygroscopic and concluded that particles of different size have a different chemical composition. Petters et al. (2009a) investigated particles produced by the burning of over 20 different biomass fuels. The particles showed a large variation in the hygroscopicity parameter $\kappa$. Similar to Dusek et al. (2005), they also found that larger particles (250 $\mathrm{nm}$ in diameter) were less hygroscopic than particles smaller than $100 \mathrm{~nm}$, concluding that the larger ones consisted mainly of soot, i.e. a mixture of elemental and organic carbon, whereas the smaller ones consisted of a mixture of organic and inorganic compounds.

Freshly emitted soot has a fractal structure which can collapse under the in- 
fluence of water. Thus, the particles become more compact and their mobility diameter decreases. This collapsing of the particles is called restructuring and it might be caused by capillary condensation or the filling of cavities leading to compaction (Weingartner et al., 1995). Restructuring has been observed for different soot types (Weingartner et al., 1995, 1997; Zhang et al., 2008; Tritscher et al., 2011b).

Dusek et al. (2011) compared hygroscopicities of fresh wood burning particles from different wood types, peat and grass measured in the sub- and in the supersaturated regime. They agreed well except for the smallest investigated size (50 nm particles). The hygroscopicity parameters for this size were about a factor of two larger in the supersaturated regime than in the subsaturated regime. They assumed that this could be due to gas phase surface active organic compounds that condense on preexisting particles and get more concentrated on smaller particles. These substances would facilitate activation in the supersaturated regime by lowering the critical supersaturation.

In this study we investigate wood burning particles both directly after emission and after several hours of aging in a smog chamber. Beech, which is often used in Switzerland for heating, was burnt in a modern log wood burner and sampling was performed during different phases of the burning cycle: starting, flaming and smoldering. The hygroscopic properties in the sub- as well as in the supersaturated regime were investigated and the deduced hygroscopicity parameters $\kappa$ were compared with each other. $\kappa$ data are nowadays also used for global climate modeling, e.g. Zhang et al. (2012). For an internally-mixed aerosol particle, the overall $\kappa$ value is calculated by taking the volume-weighted sum of the $\kappa$ value of each soluble compound. Because of the large uncertainty associated with $\kappa$ values of primary and secondary organic aerosols, studies such as ours are invaluable in order to better constrain $\kappa$ values for them and be able to distinguish $\kappa$ values according to different sources and aging times of organic particles in the atmosphere. The experiments were carried out as part of the Swiss Imbalance (IMpact of Biomass burning AerosoL on Air quality aNd ClimatE) project. Within this project, emissions of biomass burning are investigated with respect to their chemical and physical properties in field measurements, modeling studies, and laboratory studies as described herein.

In this paper we address the following questions: How well does the $\kappa$ value of freshly emitted particles agree with those from other studies, i.e. with $\kappa$ values for different wood types and burning phases? What is the influence of restructuring on the mobility diameter based hygroscopicity parameter? 
Can the hygroscopicity of the organic components be estimated? How well do the $\kappa$ values agree in the sub- and in the supersaturated regime, and what conclusions can be drawn from that?

\section{Measurement setup and instrumentation}

\subsection{Experimental setup}

The experiments were carried out in the smog chamber of the Paul Scherrer Institute (PSI). The chamber consists of a $27 \mathrm{~m}^{3}$ Teflon bag in a temperature controlled housing. The temperature was held constant at $20 \pm 1^{\circ} \mathrm{C}$ and the relative humidity $(\mathrm{RH})$ was between 57-64\%. A more detailed description of the PSI smog chamber can be found in Paulsen et al. (2005).

Beech wood was burnt in a modern log wood burner (Attika Avant, 2009). Emissions from the chimney were injected into the chamber using a heated inlet system including an ejector dilution system to reduce particle coagulation (first dilution step, dilution ratio $\approx 1: 7$ ). A detailed description of the burner, the inlet and the smog chamber setup can be found in Heringa et al. (2011). After the characterization of the primary aerosol particles, four xenon arc light sources of $4 \mathrm{~kW}$ each were turned on to simulate solar radiation and induce photochemical reactions, resulting in SOA formation (Heringa et al., 2011). From here on, time is set to zero when the lights were turned on. Thus, throughout the manuscript, time refers to 'Time After Lights On'. The duration of the experiments was between 5 to $7 \mathrm{~h}$, with one long experiment lasting for $14 \mathrm{~h}$, for details see Table 1 . The experimental setup, including the smog chamber and the instruments described in this work, is displayed in Figure 1.

\subsection{The cloud condensation nuclei counter (CCNC)}

The instrument used to measure the cloud condensation nuclei (CCN) number concentration is a continuous-flow streamwise thermal gradient $\mathrm{CCN}$ counter (CCNC). It is built and distributed by Droplet Measurement Technologies (DMT, Boulder, CO, USA). A constant supersaturation $(S S)$ in the range between $0.1 \%-2 \%$ is established by applying a constant temperature gradient across the chamber. Aerosol particles passing the chamber experience this supersaturation, and those growing to diameters larger than 1 $\mu m$ are counted as CCN at the outlet of the supersaturated column with an 


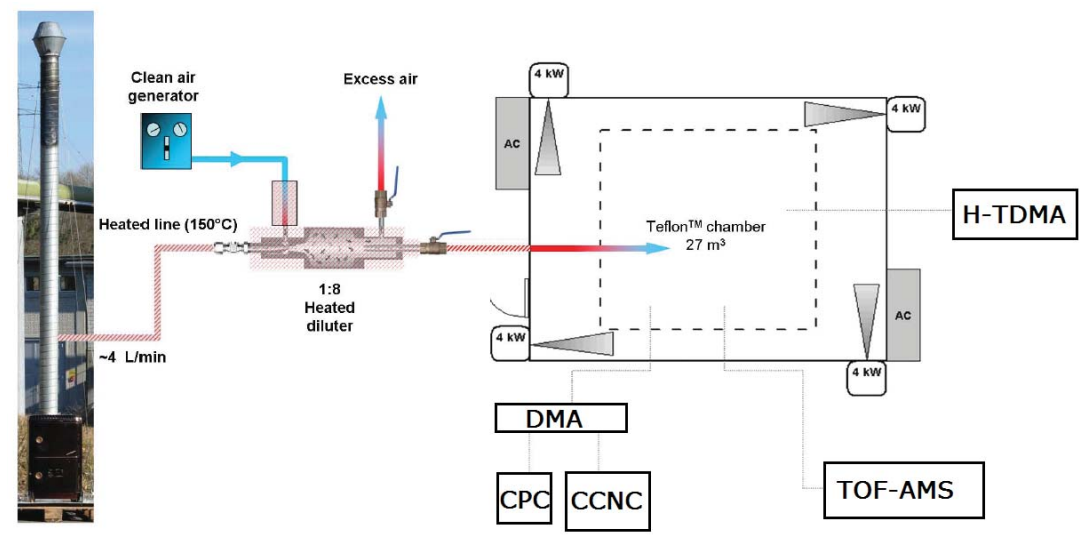

Figure 1: A sketch of the setup of the wood burning measurements, including the burner, smog chamber and instruments that were measuring. Adopted from Heringa et al. (2011).

optical particle counter. Its working principle is described in full detail by Roberts and Nenes (2005).

A differential mobility analyzer (DMA) was applied upstream of the CCNC to select one single particle size as monodisperse particles were investigated. The CCNC was deployed in parallel with a condensation particle counter (CPC, TSI 3022), which measured the total particle number concentration $\left(N_{\text {tot }}\right)$.

The CCNC was calibrated with monodisperse ammonium sulphate particles several times during the experiments, where the dry critical diameter $\left(D_{\text {crit }}\right)$, defined as the diameter at which $50 \%$ of the singly charged particles activate, was determined by fitting the activation ratio versus the dry particle size with the sum of two sigmoidal curves. This was applied in order to consider the effect of the doubly charged particles. The supersaturation in the chamber for a certain temperature gradient was then calculated from the corresponding $D_{\text {crit }}$ using the ADDEM model (Topping et al., 2005). A more detailed description of calibration procedures for the DMT CCNC can be found in Rose et al. (2008).

For the wood burning particles, measurements at different monodisperse, dry mobility diameters $\left(D_{0}\right)$ were performed. For each particle size, different $S S$ were scanned. With increasing $S S$, the activation ratio (fraction of activated particles, $\left.A R=\frac{N_{\mathrm{CCN}}}{N_{\mathrm{tot}}}\right)$ increases from 0 (non-activation) to 1 (full activation). Thus, an activation curve was obtained by plotting the activation ratio against the $S S$ for one constant size. The $S S$ at which $50 \%$ of the 
particles activate is taken as $S S_{\text {crit }}$. $S S_{\text {crit }}$ is a measure for the hygroscopicity of the investigated particles, as a larger $S S_{\text {crit }}$ means that for a given size the particles are less CCN active and need a higher $S S$ to activate to cloud droplets. The selected quasi-monodisperse particle diameters were varied between 50 to $200 \mathrm{~nm}$, and each scan through the $S S$ lasted for about 30 minutes.

The deviation between the several calibrations was $<6 \%$, which can be regarded as the main uncertainty for the CCN measurements. This leads to an uncertainty in $\kappa$ values between $12-15 \%$.

\subsection{The hygroscopicity tandem differential mobility analyzer (H-TDMA)}

The hygroscopicity tandem differential mobility analyzer (H-TDMA) measured the hygroscopic growth of particles in the subsaturated regime at a certain high $\mathrm{RH}$, which was set to $95 \%$ in this study. The particles were first dried in a diffusion dryer to a $\mathrm{RH}<15 \%$ and passed through a Kr-85 bipolar charger. A first DMA selects particles of one particular $D_{0}$, which can be changed from scan to scan. The $\mathrm{RH}$ was always $<15 \% \mathrm{RH}$ before the first DMA at a temperature of $20^{\circ} \mathrm{C}$ with a fluctuation of $\pm 0.1^{\circ} \mathrm{C}$. The quasimonodisperse particles pass through a humidifier that is set to the above mentioned 95\% RH. Downstream of the humidifier, a second DMA coupled with a CPC scanned through the humidified particle size distribution of the initially selected monodisperse particles. The housing that hosts the DMAs is temperature controlled and kept at $20^{\circ} \mathrm{C}$. The diameter of the investigated particles was varied between 35 to $300 \mathrm{~nm}$. The time resolution of the instrument for one size scan was about 7 min with a residence time of $26 \mathrm{sec}$ in the humidified region.

Additionally, a pre-humidifier consisting of a closed-bottle with a GoreTex tube submerged in MilliQ water was optionally deployed upstream of the described setup. With this, particles that have a fractal shape might collapse before they are dried, thus becoming more compact.

The accuracy of the H-TDMA was verified several times using pure ammonium sulfate particles, and the dry growth factor calibration was done after each experiment. RH values ranging from $93 \%$ to $97 \%$ were recalculated to 95.0\% RH as described in Gysel et al. (2009).

With this setup, the growth factor (GF) of a particle can be measured. GF is defined as:

$$
\mathrm{GF}=\frac{\mathrm{D}(\mathrm{RH})}{\mathrm{D}_{0}}
$$


where $D(\mathrm{RH})$ is the humidified particle mobility diameter measured by the second DMA. The uncertainty of the GF measurements was determined from the calibrations and was $<1 \%$. This leads to an uncertainty in $\kappa$ values between $5-10 \%$. Details of the H-TDMA data evaluation, the TDMAinv data inversion procedure and the determination of the growth factors can be found in Gysel et al. (2009). The H-TDMA instrument deployed during the measurements is described in full detail in Tritscher et al. (2011a).

\subsection{Further instrumentation}

The non-refractory chemical composition of submicron particles and the $\mathrm{O}: \mathrm{C}$ ratio of the organic aerosols were determined using an Aerodyne high resolution time-of-flight aerosol mass spectrometer (HR-ToF-AMS). A detailed description on the AMS measurements of this study can be found in Heringa et al. (2011). The aerosol light absorption coefficients were determined with a multi angle absorption photometer (MAAP, Thermo model 5012, Thermo-Scientific, MA, USA), with which the BC mass concentration were derived using a mass specific absorption cross section of $6.6 \mathrm{~m}^{2} \mathrm{~g}^{-1}$.

\subsection{The experiments}

In total nine experiments were carried out, where three different burning phases were sampled: 1) starting phase, where particles were injected into the chamber directly after the fire was lit, 2) flaming phase, when the fire was completely burning before the particles were injected into the chamber, 3) smoldering conditions, which is the least efficient form of combustion occurring at rather low temperatures (Reid and Hobbs, 1998). The different phases of the burning cycle were determined visually. Sampling during flaming phase experiments was started a few minutes after the moment that all wood logs were completely covered with flames. For the smoldering phase experiments, sampling was started after all flames disappeared and only glowing material was left.

After injection of the emissions in the chamber, a mixing time of 15 minutes was allowed before the lights in the smog chamber were switched on. $\mathrm{BC}$ and organic matter decreased during this time because of wall losses. When the lights were turned on, due to SOA formation more organic matter is produced than lost to the walls, which leads to an overall increase in organic matter. After the first hour, the rate of production of organic matter decreases, and after typically two hours the wall loss rates exceeds SOA production rates. This is reflected in a slow decrease in the organic matter 
concentration (Heringa et al., 2011).

The particle number is relatively high with high fluctuations during the first minutes after filling. It decreases with time due to wall losses and coagulation of particles in the chamber. Small particles decrease faster (because of higher Brownian motion they are more likely to coagulate), which leads to a particle diameter growth in the overall particle size distribution. The particles grow additionally due to SOA uptake.

The dilution of the exhaust during chamber filling was chosen to obtain particle mass concentrations similar to ambient conditions in order to have a representative gas-to-particle partitioning of semi-volatile components and thus representative particle composition and hygroscopicity. No further dilution was applied after filling, such that the trends of particle hygroscopicity with aging are not driven by dilution effects.

In some experiments only the gas phase was investigated, using a mixture of the starting and the flaming phase emissions. The separation of the gas phase was achieved by placing a heated particle filter in front of the chamber. The intention of these gas phase experiments was to investigate only the secondary aerosols that form inside the chamber from the emitted VOCs. A more detailed description of the experiments and the conditions at which they were carried out as well as a chemical characterization can be found in Heringa et al. (2011).

Three starting phase experiments, two flaming phase experiments, three pure gas phase experiments (where the primary particles were eliminated with a filter, see above), and one smoldering phase experiment were investigated, with an aging time of five to seven hours. During one pure gas phase experiment the particles were investigated for approximately $14 \mathrm{~h}$.

The investigated particle sizes for both, CCNC and H-TDMA measurements, were $D_{0}=35,50,75,100,150,200$ and $300 \mathrm{~nm}$. The measured sizes were chosen individually in each experiment to match best the maximum of the particle size distribution in the smog chamber, which was different for different experiments and also changed with aging time when the particles became larger. The duration of the experiments and the experiment numbers as used by Heringa et al. (2011) are listed in Table 1. The experiments named pure SOA in Heringa et al. (2011) are named pure gas phase here, as also inorganic material was present. 
Table 1: List of the different experiments, burning conditions, investigated phase ("both phases" refers to particle and gas phase), and their duration. Experiment numbers are given as used by Heringa et al. (2011).

\begin{tabular}{|l|l|l|l|}
\hline Burning Condition & Investigated Phase & $\begin{array}{l}\text { Duration of Experiment } \\
{[\mathrm{h}]}\end{array}$ & Experiment Number \\
\hline \hline flaming & both phases & 5.5 & 11 \\
flaming & both phases & 6 & 12 \\
starting/flaming & pure gas phase & 6 & 14 \\
starting & both phases & 7 & 15 \\
starting & both phases & 7 & 16 \\
starting & both phases & 6 & 17 \\
smoldering & both phases & 6 & - \\
starting/flaming & pure gas phase & 6 & 18 \\
starting/flaming & pure gas phase & 14 & 19 \\
\hline
\end{tabular}

\section{Hygroscopicity parameter $\kappa$}

The so-called $\kappa$ value as introduced by Petters and Kreidenweis (2007) is a measure for the hygroscopicity of the particles and can be calculated using data from the CCNC or the H-TDMA, respectively. It ranges from 0 for non-hygroscopic particles to values larger than 1 for some salts (e.g. $\kappa_{\mathrm{SOA}}=$ 0.09 (Jurányi et al., 2009), $\kappa_{\left(\mathrm{NH}_{4}\right)_{2} \mathrm{SO}_{4}}=0.61, \kappa_{\mathrm{NaCl}}=1.28$ (Petters and Kreidenweis, 2007) for CCNC derived $\kappa$ values). It is the single parameter in the semi-empirical water activity parameterization. It gives the water activity as a function of the dry diameter and the droplet diameter. The advantage of this value is that it allows comparison between measurements made in the sub- and in the supersaturated regime. $\kappa$ is connected to the equilibrium saturation ratio $S$ over a solution droplet as follows:

$$
S=\frac{D^{3}-D_{d}^{3}}{D^{3}-D_{d}^{3}(1-\kappa)} \exp \left(\frac{4 \sigma_{s / a} M_{w}}{R T \rho_{w} D}\right)
$$

where $D_{d}$ is the volume equivalent diameter of the dry particle, $D$ the equilibrium diameter of the droplet at the saturation ratio $S, \sigma_{s / a}$ the surface tension of the solution at the point of activation, $\rho_{w}$ the density of water, $M_{w}$ the molecular weight of water, $R$ the universal gas constant, and $T$ the absolute temperature. Note that the value $D_{d}$ can be different from the value $D_{0}$, which is the dry mobility diameter set in the DMA in the experiments. Often, spherical particles are assumed for obtaining $D_{d}$. This assumption is 
not valid for the soot particles investigated here. Thus, the $\kappa$ values obtained from the measurements will be called 'apparent $\kappa$ ' further on.

$\kappa$ of a mixed particle is defined as the sum of $\kappa$ values of all single solute components $i$ in the particle weighted by their corresponding volume frac-

tions $\epsilon_{i}=\frac{V_{i}}{V_{\text {tot }}}$, where $V_{i}$ is the volume of the single component $\mathrm{i}$ and $V_{\text {tot }}$ the total volume of the particle:

$$
\kappa_{\mathrm{tot}}=\sum_{i} \epsilon_{i} \kappa_{i}
$$

With the measurements made by the H-TDMA, the $\kappa$ value can also be calculated from the $\kappa$-Köhler equation (Petters and Kreidenweis, 2007).

In the following, it will be differentiated between $\kappa_{\mathrm{CCNC}}$ as the $\kappa$ value obtained from the CCNC data and $\kappa_{\mathrm{H}-\mathrm{TDMA}}$ as the $\kappa$ value obtained from the H-TDMA data.

The $\kappa$ value represents the intrinsic hygroscopicity of a compound or mixture. This makes it possible to directly compare measurements made at different particle sizes as well as measurements made in the sub- and supersaturated regime. However, it has for example been shown that $\kappa_{C C N C}$ is less sensitive to changes in the $\mathrm{O}: \mathrm{C}$ ratio of organic mixtures than $\kappa_{H-T D M A}$ in the range of low O:C ratios (Massoli et al., 2010). This can most likely be attributed to a smaller effect of solute-solute interactions in more dilute solutions (Petters et al., 2009b). Furthermore, higher apparent $\kappa$ values in the supersaturated regime can also be caused by the presence of slightly soluble or surface active compounds.

\section{Results and discussion}

\subsection{Hygroscopicity range of freshly emitted and aged particles}

First, the hygroscopicity values for both instruments and for all experiments were investigated for an aging time of five to seven hours. The apparent $\kappa$ values determined from the CCNC and the H-TMDA are plotted as a function of time in Fig. 2 (for comprehensiveness, the critical supersaturations and growth factors obtained from the CCNC and H-TDMA measurements, respectively, are presented in Appendix A.). The different colors show the different particle sizes selected with the DMA. The symbols indicate the experiment types, starting phase, flaming phase, pure gas phase and smoldering phase. The purple lines show lines of constant $\kappa$ values for pure BC and SOA 
particles. The apparent $\kappa$ values from all experiments range between 0.03 and 0.39 for freshly emitted particles measured with the CCNC and between 0 and 0.39 for particles measured with the H-TDMA.

The largest displayed particles $(200 \mathrm{~nm})$ are at least a factor of 2 less hygroscopic in apparent $\kappa_{\mathrm{CCNC}}$ than the smaller particles, while the difference is less pronounced in the H-TDMA data. Except for the smoldering phase experiment, the smallest particles $(50 \mathrm{~nm}$ ) have the highest hygroscopicities, which is more clearly seen in the H-TDMA data. The difference between the two measurement devices will be discussed in section 4.5. There is no clear difference in the hygroscopicities between the flaming, pure gas phase and starting phase, suggesting that particles of similar hygroscopicities are produced during the different burning phases. There is a variation in apparent $\kappa$ between individual experiments with the same settings that were carried out on different days. The variability in different experiments is sometimes larger $(>30 \%)$ than that of the different burning phases, and also larger than the estimated uncertainty in $\kappa$ given in subsection 2.2 and subsection 2.3 , respectively. This is the result of the large variability in burning conditions that occur when burning wood logs. A clear difference is seen for the smoldering phase experiment, where the hygroscopicities are highest at the beginning, starting with an apparent $\kappa$ of approximately 0.39 . This is the highest value for all experiments, and the apparent $\kappa$ values decrease with time. This will be discussed in detail later on.

The apparent $\kappa$ values of the freshly emitted particles lie in the same range as reported from other laboratory studies for freshly emitted biomass burning particles. To our knowledge, no hygroscopicity studies on aging processes of wood burning particles exist which include their own VOC emissions, nor a detailed investigation of particles produced from burning beech wood. Andreae and Rosenfeld (2008) report that biomass burning particles have a wide $\kappa$ range from 0.01 for fresh, soot-rich particles up to 0.55 for grass burning. Petters et al. (2009a) investigated a large variety of freshly emitted particles from burning different wood species. Our results are at the lower end of their $\kappa$ value range, which varies between 0.02 and 0.8. DeMott et al. (2009) derived $\kappa$ from H-TDMA data from particles of biomass combustion and obtained a range from 0.02 to 0.56 . However, in both studies different parts of the plants were burnt, like leaves or needles, whereas in our measurement log wood was used. Thus, the experiments are not directly comparable as they have different initial conditions. Furthermore, no SOA production from own VOC emissions was investigated there. 


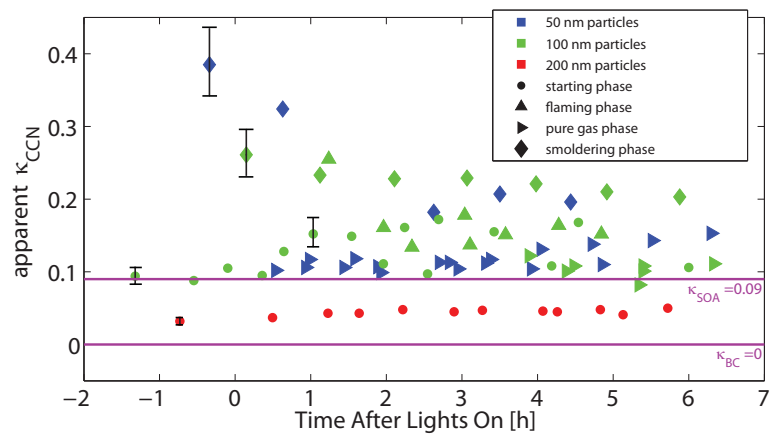

(a)

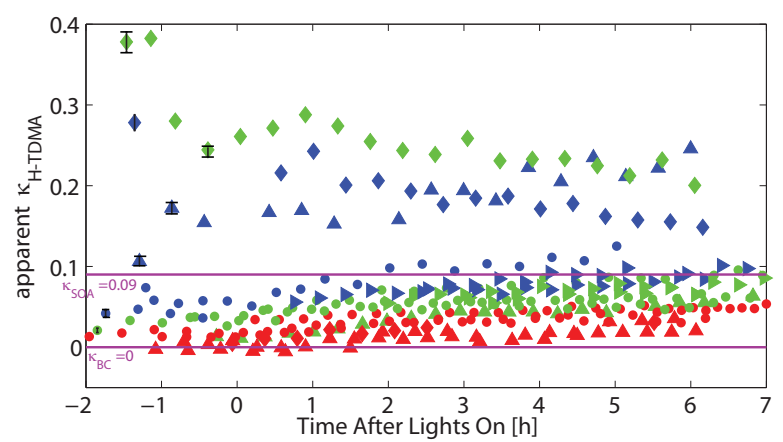

(b)

Figure 2: Apparent $\kappa$ hygroscopicity parameter for the CCNC (a) and the H-TDMA (b) data for 50, 100 and $200 \mathrm{~nm}$ particles for all conducted experiments. The error bars of the $\kappa$ values are inferred from the measurement uncertainties as described in the text. For clarity of the graph, only some error bars were plotted exemplarily.

The different hygroscopicities for different mobility diameters suggest that the particles have a different chemical composition and/or different morphology, with the larger particles (200 $\mathrm{nm}$ in diameter) containing a larger fraction of non-hygroscopic compounds, like BC. They may also contain a smaller fraction of the more hygroscopic organic and/or inorganic compounds. Dusek et al. (2011) report an average $\kappa$ of 0.1 for $50 \mathrm{~nm}$ particles, 0.08 for $100 \mathrm{~nm}$ particles, and 0.06 for $150 \mathrm{~nm}$ particles for freshly emitted particles of different hard- and softwood fuels. Similar to our findings, hygroscopicities decreased with increasing particle size. Pósfai et al. (2003) analyzed single wood burning particles and found a majority of organic particles with different amounts of inorganic inclusions in fresh smoke. Furthermore, chain-like 
soot aggregates were detected, which were relatively small $(20-50 \mathrm{~nm})$ in the fire, but formed larger aggregates shortly afterwards. Also so-called 'tarballs', which are spherical particles containing mainly black carbon, were found. The reason for the different hygroscopicities for different sizes could be that larger particles consist mainly of soot agglomerates, whereas the smaller particles contain relatively more organic compounds and might also contain more inorganic salts, which agrees well with results described by Petters et al. (2009a, and references therein). It can also be caused by the fact that the larger particles restructure more.

The large variance of apparent $\kappa$ values found during this study indicates that it is not possible to reduce the hygroscopicity parameter $\kappa$ to one value for the different burning phases. The measured values are most of the time larger than $\kappa$ of $\mathrm{BC}$, and often higher than $\kappa$ of pure SOA particles. $\kappa \mathrm{s}$ of pure inorganic compounds are typically found around 0.6 , a value which is above the upper limit of the results reported in this study. Furthermore, a similarly large variance for different wood types reported in the studies mentioned above also indicates that $\kappa$ cannot be reduced to one value for different wood types.

The hygroscopicities of the investigated particles increase with aging as expected, except for the smoldering phase experiment. This increase is most of the time more pronounced in the H-TDMA data and it differs with size and experiment for both regimes. It is least pronounced in the $200 \mathrm{~nm}$ particles, which should have the largest BC mass fraction, as argued above.

\subsection{Restructuring of soot particles}

Fractal particles can restructure when exposed to high $\mathrm{RH}$, which in turn can lead to a decrease in their mobility diameter. When the pre-humidifier is applied upstream of the H-TDMA instrument, particles can already restructure before they are size-selected by the first DMA. We assume that this restructuring is not reversible after drying. For the same experiment, measurements with and without the pre-humidifier were conducted. The apparent $\kappa$ of experiment 11 and 17 is exemplarily shown in Fig. 3. Fig. 3(a) displays an example, where restructuring is seen for 200 and $300 \mathrm{~nm}$ particles (indicated by the higher apparent $\kappa$ values for the open symbols), Fig. 3(b) one where it is not seen. The different colors indicate the different sizes of the investigated particles and the open and filled symbols the data points with and without pre-humidifier upstream of the H-TDMA, respectively. Restructuring was only found during some of the experiments, and never for 
particles $<100 \mathrm{~nm}$. Negative $\kappa$ values in Fig. 3(a) are caused by restructuring under the influence of high relative humidity in the H-TDMA, which leads to a shrinkage of the particle and thus to $\mathrm{GF}<1$. Although restructuring was observed only in 3 out of 6 experiments where primary particles were present, it cannot be ruled out that the particles do not restructure during the other experiments in the humidifier. With the same instrumental setup, restructuring was also observed for soot particles emitted from Diesel cars (Tritscher et al., 2011b). Thus the measured apparent $\kappa$ or rather GF values provide a lower limit for the true hygroscopicity of fractal-like particles due to water uptake.

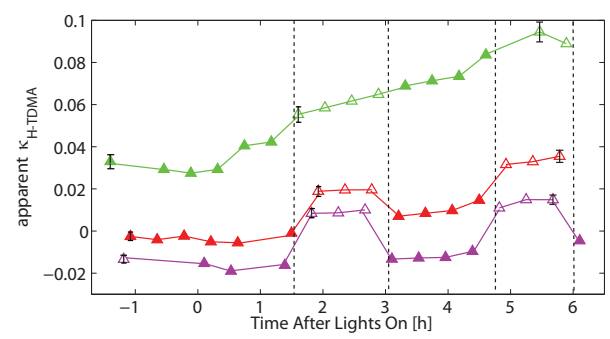

(a)

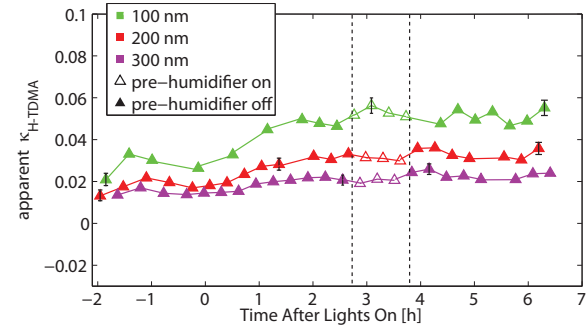

(b)

Figure 3: Experiment no. 11 (a) is shown as an example where restructuring was observed for particles with large $D_{0}$. For the larger particles the apparent $\kappa$ values are higher when the pre-humidifier is applied upstream of the H-TDMA setup (open symbols). Experiment no. 17 (b) is shown as an example where no restructuring was observed. Error bars are depicted exemplarily.

\subsection{Long aging for a pure gas phase experiment}

For investigation of the temporal evolution of the secondary organic and inorganic aerosol components formed from the gaseous precursors without interference from primary particles over a longer time scale, an experiment (Exp. no. 19) was conducted where the particles were investigated in the chamber over a time period of $14 \mathrm{~h}$. These secondary particles can be assumed to be spherical, as only gas phase was injected into the chamber during this experiment and no primary soot particles were present. Thus, $\kappa$-Köhler theory is better applicable in this case where no shape factors have to be considered. In Fig. 4, the $\kappa$ values versus the time line obtained from the CCNC and the H-TDMA measurements are displayed. 


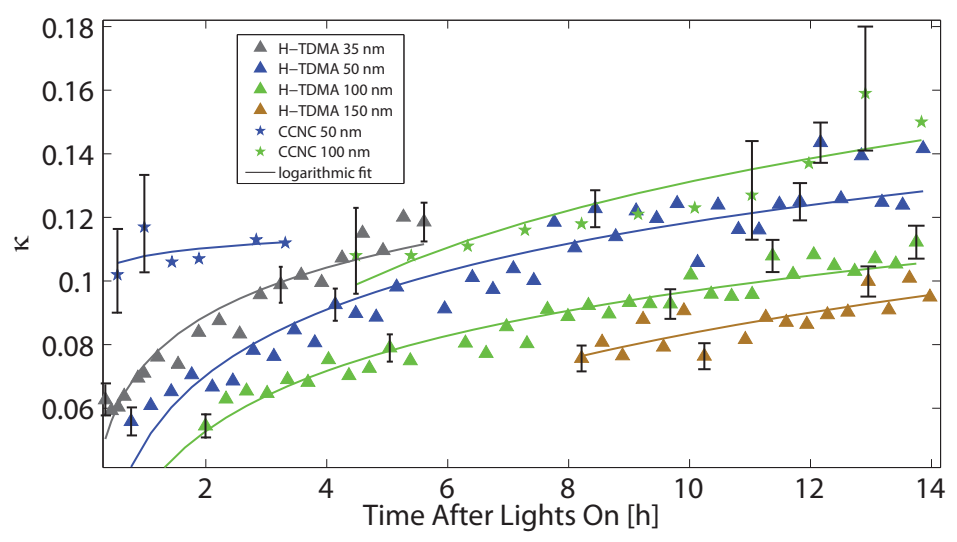

Figure 4: $\kappa$ values of the long pure gas phase experiment as a function of time. The $\kappa$ values from the H-TDMA and the CCNC are displayed. The different colors indicate the different sizes, and the different symbols the data from the two instruments. Error bars are depicted exemplarily.

The different colors indicate the different particle sizes, and the different symbols the data from the two instruments. The CCNC measured $50 \mathrm{~nm}$ particles at the beginning. Later, after the particles grew to larger sizes, $100 \mathrm{~nm}$ particles were investigated. $\kappa_{\mathrm{CCNC}}$ of the $50 \mathrm{~nm}$ particles started at 0.1 , and increased gradually. The $100 \mathrm{~nm}$ particles had at the beginning a slightly lower hygroscopicity than the $50 \mathrm{~nm}$ particles, starting at 0.1 after $\approx 4 \mathrm{~h}$ after lights on. $\kappa$ also increased gradually over the first $12 \mathrm{~h}$. The H-TDMA measured 35, 50, 100 and $150 \mathrm{~nm}$ particles. They all started at low $\kappa$ values which increased with time, with the smallest particles having the highest $\kappa$ values. The lines are logarithmical fits of the data (in the form of $m \cdot \ln$ (Time After Lights On) $+t$, with $m$ and $t$ being the fit parameters). The fits represent the H-TDMA data series well $\left(R^{2} \geq 0.9\right)$, except for the $150 \mathrm{~nm}$ data, which start later. The $50 \mathrm{~nm}$ CCNC data cannot be fitted well $\left(R^{2}<0.5\right)$. The $50 \mathrm{~nm}$ data ends after $\approx 4 \mathrm{~h}$, when the $\mathrm{O}: \mathrm{C}$ ratio is still $<0.4$. At those low $\mathrm{O}$ : $\mathrm{C}$ ratios, the $\kappa$ of the particles in the supersaturated regime are not very sensitive to an increase in the O:C ratio (Massoli et al., 2010). The fit is better $\left(R^{2}=0.77\right)$ for the $100 \mathrm{~nm}$ particles, but still not as good as for the H-TDMA data. The reason for this might also be the low O:C ratios at the beginning of the data series. This graph also shows a clear discrepancy between the CCNC and the H-TDMA data, with the CCNC measuring significantly higher $\kappa$ values than the H-TDMA. This will 
be discussed in detail in section 4.5. The increase in $\kappa$ with time is due to the condensation of oxidized organic or inorganic matter from the gas phase on the particles, and due to the oxidation of the organic particulate matter itself. The $\kappa$ values do not reach a plateau during the investigated time period. It can thus be assumed that the particles would still become more hygroscopic by further aging, which is also suggested by the fits. The high $\kappa$ values indicate also that inorganic trace gases such as $\mathrm{SO}_{2}$ and $\mathrm{NO}_{\mathrm{x}}$ were emitted in the gas phase and contributed to particle mass after oxidation.

Using the bulk AMS measurements, $\kappa_{\mathrm{H}-\mathrm{TDMA}}$ and $\kappa_{\mathrm{CCNC}}$ of the organic fraction $\left(\kappa_{\text {org }}\right)$ for $100 \mathrm{~nm}$ particles could be estimated for this experiment. The results can be compared with $\kappa_{\text {org }}$ values found for other studies of SOA particles. It can also be used to estimate total $\kappa$ values from other wood burning experiments if composition data is available, as to our knowledge $\kappa$ of the organic compounds of wood burning particles has not been determined before. For the estimation it was assumed that all the measured $\mathrm{NH}_{4}$ was present as $\left(\mathrm{NH}_{4}\right)_{2} \mathrm{SO}_{4}$. Approximately $65 \%$ of the measured sulfate fragments could then be neutralized as $\left(\mathrm{NH}_{4}\right)_{2} \mathrm{SO}_{4}$, and the remaining fragments as well as the nitrate fragments were assumed to have been present in organic compounds.

The inorganic mass concentration measured with the AMS was $<0.9 \mu \mathrm{g} \mathrm{m}^{-3}$, and the organic mass concentration was $\leq 7 \mu \mathrm{g} \mathrm{m}^{-3}$. The latter decreased with time towards $5.7 \mu \mathrm{g} \mathrm{m}^{-3}$ at the end of the experiment due to wall losses. See Heringa et al. (2011) for a thorough description of the used chemical data. The density for $\left(\mathrm{NH}_{4}\right)_{2} \mathrm{SO}_{4}$ was taken from Topping et al. (2005). Its $\kappa$ value for $100 \mathrm{~nm}$ particles, which was derived from predicted growth factors at 90\% RH with the ADDEM model (Topping et al., 2005), was taken from Good et al. (2010). The density of the organic compounds was assumed to be $1270 \mathrm{~kg} \mathrm{~m}^{-3}$ (Cross et al., 2007). The Zdanovskii, Stokes and Robinson (ZSR) assumption (Stokes and Robinson, 1966) was applied to calculate $\kappa_{\text {org }}$ based on Equation 3, assuming that an organic fraction and $\left(\mathrm{NH}_{4}\right)_{2} \mathrm{SO}_{4}$ was present.

The $\kappa_{\text {org }(\mathrm{H}-\mathrm{TDMA})}$ and the $\kappa_{\mathrm{org}(\mathrm{CCNC})}$ for $100 \mathrm{~nm}$ particles plotted against the $\mathrm{O}: \mathrm{C}$ ratio is displayed in Fig. 5. The O:C ratio was obtained from the AMS and is a proxy for the oxidation level of organic aerosols (Massoli et al., 2010). The colors indicate the aging time, i.e. the time after lights on. The $\kappa_{\text {org }}$ values increase with aging time in the smog chamber, reaching up to 0.07 after $14 \mathrm{~h}$ of aging for the H-TDMA, and values around 0.10 for the CCNC. The uncertainty of $\kappa$ was calculated based on the uncertainty of SS of $6 \%$ 
(see section 2.2) and that of the growth factor of $1 \%$ (see section 2.3), i.e. $\kappa_{\text {org }} \pm \Delta \kappa_{\text {org }}$, was inferred from $S S \pm \Delta S S$ or from $G F \pm \Delta G F$, respectively. It can be assumed from the graph that the $\kappa_{\text {org }(\mathrm{H}-\mathrm{TDMA})}$ would increase further with further aging. The $\kappa_{\text {org }(\mathrm{CCNC})}$ values are higher than the $\kappa_{\text {org }(\mathrm{H}-\mathrm{TDMA})}$ values. A lower $\kappa_{\text {org }(\mathrm{H}-\mathrm{TDMA})}$ than $\kappa_{\mathrm{org}(\mathrm{CCNC})}$ of $20 \%$ to $50 \%$ of SOA particles is also reported by Massoli et al. (2010). A similar discrepancy is reported by Dusek et al. (2011) for $50 \mathrm{~nm}$ wood burning particles, but they report a better agreement for $100 \mathrm{~nm}$ particles. Furthermore, the $\kappa_{\mathrm{org}(\mathrm{CCNC})}$ values are not sensitive to an increase in the $\mathrm{O}: \mathrm{C}$ ratio until approximately $10 \mathrm{~h}$ after the lights were turned on, or an $\mathrm{O}: \mathrm{C}$ ratio of the organic fraction of 0.41 . This is comparable to results from Massoli et al. (2010), who report that $\kappa_{\mathrm{org}(\mathrm{CCNC})}$ is rather insensitive to $\mathrm{O}: \mathrm{C}$ ratios below $\approx 0.5 . \kappa$ values around 0.1 are often found as representative of SOA (Gunthe et al., 2009; Jurányi et al., 2009; Dusek et al., 2010). When comparing the $\kappa_{\text {org }}$ to O:C ratio relationship with those from other laboratory and field studies as summarized in Jimenez et al. (2009), $\kappa_{\text {org }}$ obtained in our study lies well within the range of those measurements. In an O:C range from 0.38 to 0.44 , the $\kappa_{\text {org(H-TDMA) }}$ data presented here fits very well with the $\alpha$-pinene- $\kappa_{\text {org(H-TDMA) }}$ data between $0.035-0.07$ presented there.

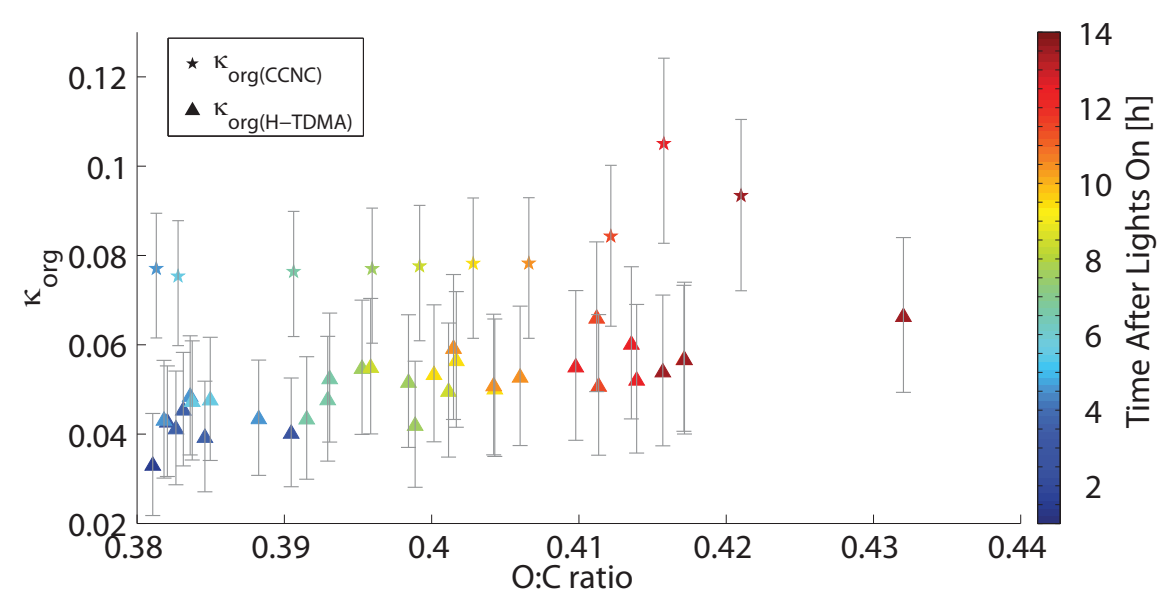

Figure 5: The estimated $\kappa_{\mathrm{org}(\mathrm{H}-\mathrm{TDMA})}$ and $\kappa_{\mathrm{org}(\mathrm{CCNC})}$ values for $100 \mathrm{~nm}$ particles versus the O:C ratio of the organic fraction derived from AMS data. The colors indicate the aging time in hours. The error bars represent the uncertainty in the hygroscopicity measurements. 


\subsection{Wood burning smoldering phase experiment}

Smoldering is the burning phase which occurs at lower temperatures than the flaming phase and is mainly a surface process, where oxygen reacts exothermically with carbon (Reid and Hobbs, 1998). It is also the least efficient combustion mode, where the components of the wood are not as effectively burnt as during the other phases (Hays et al., 2002). Gao et al. (2003) found more organic species in the particulate phase for smoldering fires compared to flaming fires, whereas the inorganic species did not show a clear difference between the flaming and the smoldering phase. Reid and Hobbs (1998) report that the soot fraction is smaller than during the flaming phase, and that the particles are predominantly formed by the condensation of VOCs.

Different from other smoldering phase experiments described in the literature, the one investigated here was a smoldering phase that occurred after the flaming phase. This might lead to a different chemical composition of the emitted particles as most of the organics were already burnt and inorganic species became more important. The AMS showed a higher $\mathrm{NO}_{3}$ fraction for this experiment than for the others. It was highest after $2 \mathrm{~h}$ of aging time and slowly decreased afterwards. The organic fraction was below $3 \mu \mathrm{g} / \mathrm{m}^{3}$ during the experiment, $\mathrm{NO}_{3}$ below $1 \mu \mathrm{g} / \mathrm{m}^{3}$ and the $\mathrm{SO}_{4}$ fraction stayed close to $0 \mu \mathrm{g} / \mathrm{m}^{3}$. The average $\mathrm{BC}$ concentration as measured with the MAAP was $0.31 \mathrm{\mu gm}^{-3}$, with a standard deviation of the instrument noise of 0.32 $\mu \mathrm{gm}^{-3}$. Thus, no significant concentration of BC was measured, which is to be expected for smoldering phase experiments. Qualitatively more potassium was measured as well with the AMS, and the organic fraction was lower than for the other experiments. To distinguish it from other smoldering phase experiments, it will be called wood burning smoldering further on.

The temporal development of apparent $\kappa$ during this experiment is shown in Fig. 6. The $100 \mathrm{~nm}$ particles are the most hygroscopic ones, and also the apparent $\kappa$ values for $50 \mathrm{~nm}$ particles are higher than those for the other experiment types. The hygroscopicity of the $200 \mathrm{~nm}$ particles is similar to that obtained for $200 \mathrm{~nm}$ particles from the other burning phases. The smoldering phase experiment was also the only experiment during which the apparent $\kappa$ values were highest at the beginning of the experiment and then decreased with time. For $100 \mathrm{~nm}$ particles, apparent $\kappa_{\mathrm{CCNC}}$ was around 0.26 when the lights were turned on, and around 0.22 after $2.1 \mathrm{~h}$.

The decrease in hygroscopicity and the high starting values for the apparent $\kappa$ is likely due to a higher inorganic mass fraction during this experiment 


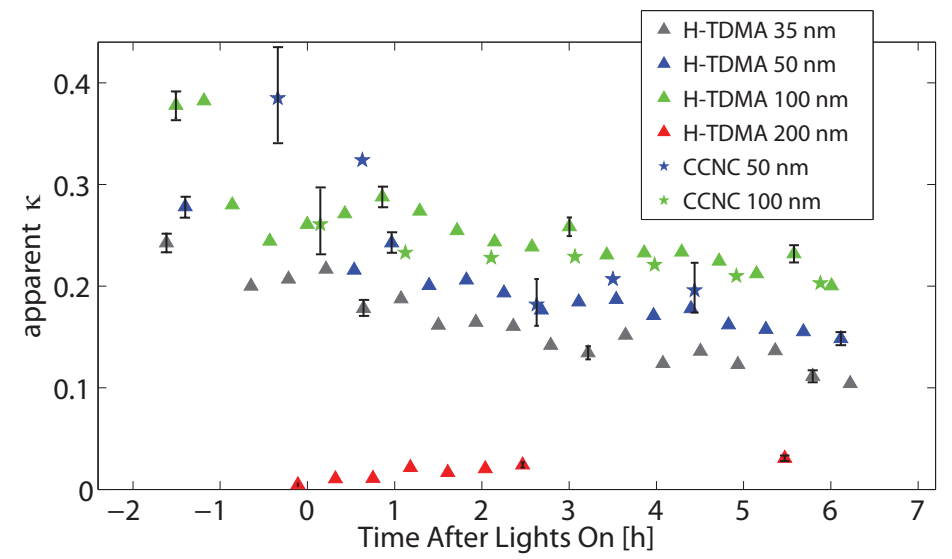

Figure 6: Timeline of the wood burning smoldering phase experiment. The apparent $\kappa$ values for the H-TDMA and for the CCNC are displayed. Error bars are depicted exemplarily.

as measured with the AMS. With time, more gaseous organic material condenses on the preexisting particles and the hygroscopicity decreases. No indication of an external mixture of the particles was seen by the H-TDMA. Thus, the higher values for the $100 \mathrm{~nm}$ particles are most likely caused by a higher inorganic fraction. The $200 \mathrm{~nm}$ particles exhibited very small apparent $\kappa_{\mathrm{H}-\mathrm{TDMA}}$ in contrast to the high apparent $\kappa$ values observed for particles with diameters $\leq 100 \mathrm{~nm}$. It could be that only a minor fraction of the particles contained a substantial $\mathrm{BC}$ core and that only those particles reached $200 \mathrm{~nm}$ in diameter. This would then result in small apparent $\kappa$ values due to the high fraction of insoluble $\mathrm{BC}$ and due to additional shape effects. However, size dependent composition data needed to corroborate this speculation are not available.

This experiment was only carried out once, therefore a repetition of this setup would be desirable. Furthermore, the particle concentration in the smog chamber was very low during this experiment, which increases the uncertainty in the AMS mass measurements.

\subsection{Comparison of the apparent $\kappa$ values obtained from CCNC and H-TDMA measurements}

In the following, the apparent $\kappa$ values obtained in the sub- and supersaturated regime are compared. Plots of apparent $\kappa_{\mathrm{CCNC}}$ versus apparent 
$\kappa_{\mathrm{H}-\mathrm{TDMA}}$ for 50, 100 and $200 \mathrm{~nm}$ particles are shown in Fig. 7. The symbols indicate the different experiment types. The different colors of the symbol frames represent the different experiment days, and the filling color indicates the time after lights on. The solid line is the 1:1 line, the dashed lines are lines with a certain percentage deviation from this line. The percentage is written next to the line.

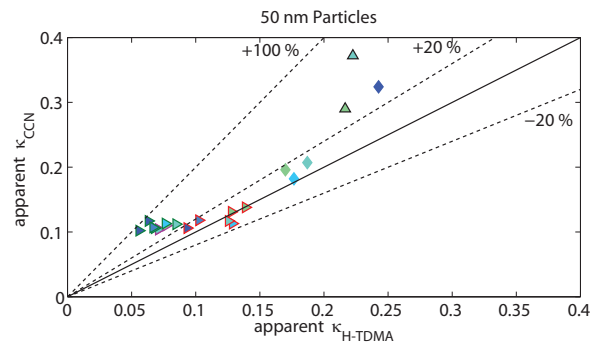

(a)

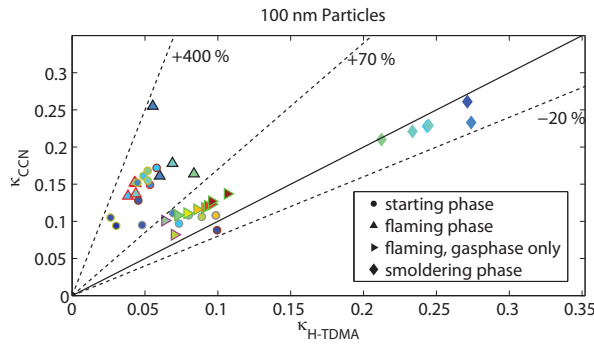

(b)

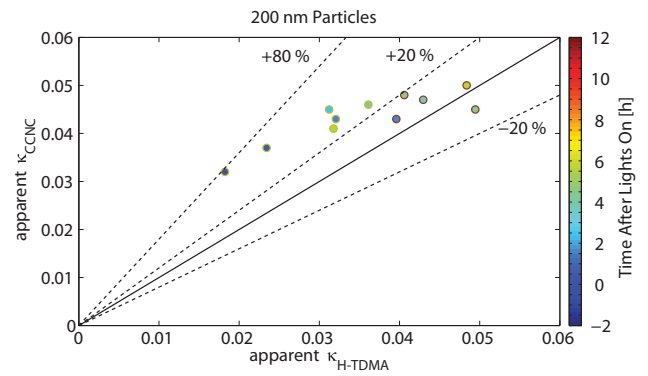

(c)

Figure 7: The hygroscopicity parameter apparent $\kappa_{\mathrm{CCNC}}$ versus apparent $\kappa_{\mathrm{H}-\mathrm{TDMA}}$ for (a) $50 \mathrm{~nm}$, (b) $100 \mathrm{~nm}$, and (c) $200 \mathrm{~nm}$ particles until $12 \mathrm{~h}$ of aging. The symbols indicate the burning phase. Different frame colors refer to different experiments. The filling color indicates the aging time. The solid line is the 1:1 line, the dashed lines are lines with a certain percentage deviation from this line. The percentage is written next to the line.

The comparison for $50 \mathrm{~nm}$ particles is displayed in Fig. 7(a). In general, apparent $\kappa_{\mathrm{CCNC}}$ are higher than apparent $\kappa_{\mathrm{H}-\mathrm{TDMA}}$. The wood burning smoldering values agree within $20 \%$, whereas the flaming and pure gas phase values show up to $100 \%$ larger apparent $\kappa_{\mathrm{CCNC}}$ values than apparent $\kappa_{\mathrm{H}-\mathrm{TDMA}}$. In Fig. 7(b), the same plot for the $100 \mathrm{~nm}$ particles is displayed. Here, the agreement is also within $20 \%$ for the wood burning smoldering phase experiment. The pure gas phase measurements agree within $70 \%$. The largest 
difference occurs for the starting and the flaming phase with discrepancies of up to $400 \%$. It can be seen that within one experiment the agreement improves with aging time as with time the condensation of organic matter makes the particles more compact reducing artifacts from morphology effects as described beforehand. Moreover, $\kappa_{\mathrm{org}(\mathrm{CCNC})}$ and $\kappa_{\mathrm{org}(\mathrm{H}-\mathrm{TDMA})}$ generally agree better for higher O:C ratios (see e.g. Massoli et al. (2010); Jurányi et al. (2009)). The comparison for $200 \mathrm{~nm}$ particles is displayed in Fig. 7(c). The agreement is better than for the $100 \mathrm{~nm}$ particles, and the starting phase experiments agree better (within 20\%) than the flaming phase experiments (with a deviation of up to $80 \%$ ).

The wood burning smoldering phase experiment has the best agreement for the two compared particle sizes, as the higher inorganic fraction of the compounds of the particles dominates their apparent $\kappa$ values. For the gas phase experiment, where only secondary aerosols were present, the agreement is worse, but still better than for the flaming phase and the starting phase experiments. The particles can be assumed to be spherical in the pure gas phase experiments, as they did not contain soot. Thus, these differences cannot be explained by morphology. As described in section 3, the difference might partly be attributed to higher $\kappa_{\mathrm{CCNC}}$ values than $\kappa_{\text {HTDMA }}$ values if slightly soluble or surface active organic substances are involved. The difference in the apparent $\kappa$ values for the flaming phase and starting phase experiments can also be caused by restructuring, which leads to a discrepancy between the apparent $\kappa$ values derived from different instruments. The discrepancy of the pure gas phase measurements $(100 \%$ for $50 \mathrm{~nm}$ particles and $70 \%$ for 100 $\mathrm{nm}$ particles) between sub- and supersaturated regime can be attributed to the discrepancy caused by the different impact of the organic matter on the hygroscopicity of the particles in the two regimes. The remaining larger difference between measurements in the sub- and in the supersaturated regime for $100 \mathrm{~nm}$ particles for flaming phase and starting phase experiments can then be caused by restructuring effects, which do not occur in the pure gas phase experiments.

\section{Conclusions and outlook}

Different wood burning experiments have been investigated in a smog chamber. Beech wood was burnt in a modern log wood burner and the

emitted and formed particles were analyzed. In particular, the hygroscopic 
parameter apparent $\kappa$ was measured in the subsaturated regime using a hygroscopic tandem differential mobility analyzer (H-TDMA), as well as in the supersaturated regime, using a cloud condensation nuclei counter (CCNC). The range found for freshly emitted particles between 0 and 0.39 compares well to $\kappa$ values found in similar studies for freshly emitted wood burning aerosols. The large range of the apparent $\kappa$ values indicates that the variability in the emissions makes it impossible to use one representative $\kappa$ value for all burning phases and investigated particle sizes. However, the $\kappa$ value of measured wood burning emissions can be estimated if composition data (consisting of black carbon, inorganic salts and organic matter data) are available when assuming that black carbon is insoluble and using the $\kappa_{\text {org }}$ value of wood burning particles estimated in this manuscript.

Using a pre-humidifier in front of the H-TDMA leads to restructuring effects for the larger $(\geq 100 \mathrm{~nm})$ particles in some of the experiments. This is due to the fractal-like structure of soot particles that become more compact in the presence of high relative humidity. It was not seen in all experiments, but cannot be excluded to have happened in all measurements. This leads to an underestimation of the hygroscopicity measured with mobility diameter based methods.

In a pure gas phase experiment, where the aging of the particles was investigated for about $14 \mathrm{~h}$, the hygroscopicity of the particles reached a maximum $\kappa$ value of about 0.15 , but was still increasing. The particles can be assumed to be spherical in this experiment and the $\kappa$ of the organic fraction could be determined. It increased with time and was found to be 0.07 after $14 \mathrm{~h}$ of aging for measurements below 100\% relative humidity and around 0.10 for measurements above. It agrees well with other $\kappa$ values found for fresh secondary organic aerosols.

During a wood burning smoldering phase experiment, the hygroscopicity decreased with time, while during all other experiments it increased as expected due to the aging of the particles. The different behavior of apparent $\kappa$ with time in the smoldering phase experiment is probably due to a different chemical composition of the particles during wood burning smoldering, i.e. them having a larger inorganic fraction.

When comparing the apparent $\kappa$ values in the subsaturated regime with those in the supersaturated regime, the apparent $\kappa$ values in the supersaturated regime are generally higher than in the subsaturated range. The apparent $\kappa$ values observed in the supersaturated regime are generally higher than those observed in the subsaturated range. This may be partially due to the 
non-sphericity of the particles. However, some difference is also observed for the spherical particles from the gas phase only experiment, indicating that the $\kappa$ value is not completely independent of water activity. The agreement between the sub- and supersaturated regimes is better for the wood burning smoldering phase experiment, where the inorganic fraction has a dominant influence on particle hygroscopicity, and where the particles are likely less non-spherical, due to a low BC mass fraction.

Further experiments should include a repetition of the wood burning smoldering phase experiment to see if our results are representative for this type of burning phase. Experiments applying longer aging times would give information on the apparent $\kappa$ that that would eventually be reached and which should be closer to atmospheric values and could be used, e.g., in cloud parcel models to simulate CCN activation (e.g., Reutter et al. (2009)). Also, the extension of the measurements to wood types from various regions of the world would improve the representativeness of the inferred $\kappa$ values with respect to hygroscopicity parameterizations in global models.

The experiments shown here were carried out using a new wood burner, and the results would most likely differ when investigating the emissions of older, less efficient log wood burners, that are still more frequently used on a global scale. Old log wood burners have a 3 to 4 times higher $\mathrm{BC}$ emission factor as shown in Heringa et al. (2011). They also have significantly higher SOA emissions during the flaming phase. The emissions of all wood burners are also very different, depending e.g. on the burnt wood, firing, set-up. In the future, however, the fraction of modern log wood burners will increase and the results presented herein are valuable in this respect.

\section{Acknowledgements}

This work was supported by the Imbalance project of the Competence Center Environment and Sustainability of the ETH Domain (CCES), The Bundesamt für Umwelt (BAFU), the Bundesamt für Energie (BFE), as well as the Swiss National Science Foundation. Attika Feuer AG is greatfully acknowledged for the provided wood stove. 


\section{Appendix A.}

For comprehensiveness of the manuscript, the critical supersaturation $S_{\text {crit }}$ and the growth factors GF as deduced from the CCNC and and H-TDMA measurements, respectively, are summarized in the Appendix. Figure A.8 displays the temporal evolution of $S_{\text {crit }}$ and GF for the individual particle sizes and experiments. The apparent $\kappa$ values, as discussed in the main text and plotted in Fig. 2, were deduced from these parameters.

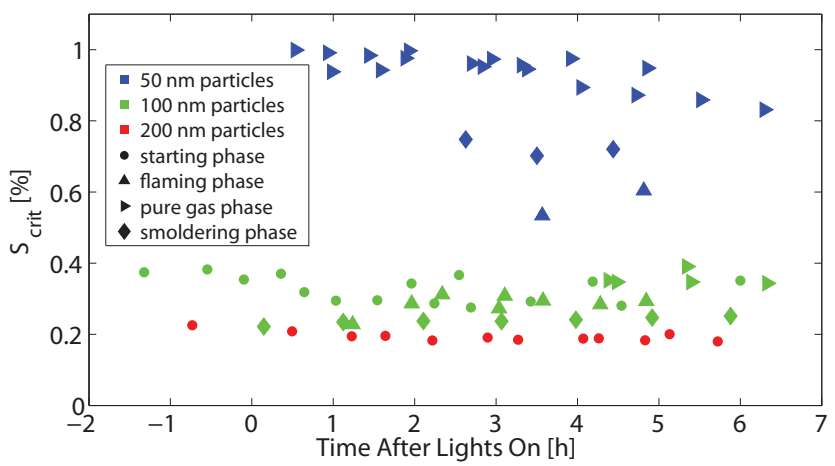

(a)

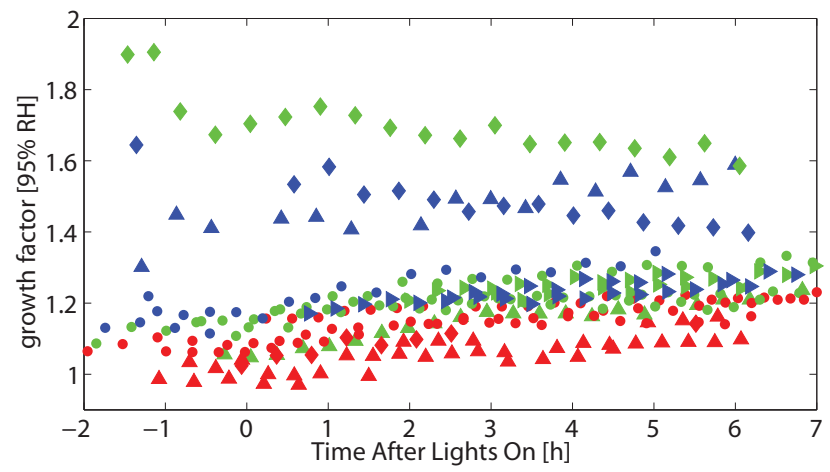

(b)

Figure A.8: Critical supersaturations of the CCNC (a) and growth factors of the H-TDMA (b) data for 50, 100 and $200 \mathrm{~nm}$ particles for all conducted experiments. 


\section{References}

Andreae, M. O., Rosenfeld, D., 2008. Aerosol-cloud-precipitation interactions. Part 1. The nature and sources of cloud-active aerosols. Earth Sci. Rev. 89 (1-2), 13-41.

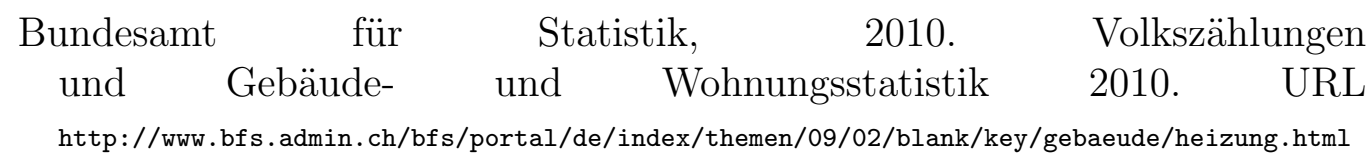

Caseiro, A., Bauer, H., Schmidl, C., Casimiro, A. P., and Puxbaum, H., 2009. Wood burning impact on $\mathrm{PM}_{10}$ in three Austrian regions. Atmos. Env. 43 (13), 2186-2195.

Cross, E., Slowik, J., Davidovits, P., Allan, J., Worsnop, D., Jayne, J., Lewis, D., Canagaratna, M., Onasch, T., 2007. Laboratory and ambient particle density determinations using light scattering in conjunction with aerosol mass spectrometry. Aerosol Sci. Technol. 41 (4), 343-359.

Decesari, S., Facchini, M. C., Matta, E., Mircea, M., Fuzzi, S., Chughtai, A. R., Smith, D. M., 2002. Water soluble organic compounds formed by oxidation of soot. Atmos.Environ. 36 (11), 1827-1832.

DeMott, P., Petters, M. D., Prenni, A., Carrico, C., Kreidenweis, S., Collett Jr., J., Moosmüller, H., 2009. Ice nucleation behavior of biomass combustion particles at cirrus temperatures. J. Geophys. Res. 114, D16205.

Duan, F., Liu, X., Yuc, T., Cachier, H. 2004. Identification and estimate of biomass burning contribution to the urban aerosol organic carbon concentrations in Beijing. Atmos. Env. 38, 9, 1275-1282.

Duplissy, J., DeCarlo, P. F., Dommen, J., Alfarra, M. R., Metzger, A., Barmpadimos, I., Prevot, A. S. H., Weingartner, E., Tritscher, T., Gysel, M., Aiken, A. C., Jimenez, J. L., Canagaratna, M. R., Worsnop, D. R., Collins, D. R., Tomlinson, J., Baltensperger, U., 2011. Relating hygroscopicity and composition of organic aerosol particulate matter. Atmos. Chem. Phys. 11, $1155-1165$.

Dusek, U., Frank, G. P., Curtius, J., Drewnick, F., Schneider, J., Kürten, A., Rose, D., Andreae, M. O., Borrmann, S., Pöschl, U., 2010. Enhanced organic mass fraction and decreased hygroscopicity of cloud condensation 
nuclei $(\mathrm{CCN})$ during new particle formation events. Geophys. Res. Lett 37, L03804.

Dusek, U., Frank, G. P., Helas, G., Iinuma, Y., Zeromskiene, K., Gwaze, P., Hennig, T., Massling, A., Schmid, O., Herrmann, H., Wiedensohler, A., Andreae, M. O., 2005. "Missing" cloud condensation nuclei in peat smoke. Geophys. Res. Lett. 32 (11), L11802.

Dusek, U., Frank, G. P., Massling, A., Zeromskiene, K., Iinuma, Y., Schmid, O., Helas, G., Hennig, T., Wiedensohler, A., Andreae, M. O., 2011. Water uptake by biomass burning aerosol at sub- and supersaturated conditions: closure studies and implications for the role of organics. Atmos. Chem. Phys. 11, 9519-9532.

Favez, O., Cachier, H., Sciare, J., Sarda-Estève, R., Martinon, L., 2009. Evidence for a significant contribution of wood burning aerosols to PM2. 5 during the winter season in Paris, France. Atmos. Env. 43, 3640-3644.

Gao, S., Hegg, D. A., Hobbs, P. V., Kirchstetter, T. W., Magi, B. I., Sadilek, M., 2003. Water-soluble organic components in aerosols associated with savanna fires in southern Africa: Identification, evolution, and distribution. J. Geophys. Res. 108(D13), 8491.

George, I. J., Abbatt, J. P. D., 2010. Chemical evolution of secondary organic aerosol from $\mathrm{OH}$-initiated heterogeneous oxidation. Atmos. Chem. Phys. $10,5551-5563$.

Good, N., Topping, D. O., Allan, J. D., Flynn, M., Fuentes, E., Irwin, M., Williams, P. I., Coe, H., McFiggans, G., 2010. Consistency between parameterisations of aerosol hygroscopicity and CCN activity during the RHaMBLe discovery cruise. Atmos. Chem. Phys. 10, 3189-3203.

Gunthe, S. S., King, S. M., Rose, D., Chen, Q., Roldin, P., Farmer, D. K., Jimenez, J. L., Artaxo, P., Andreae, M. O., Martin, S. T., Pschl, U., 2009. Cloud condensation nuclei in pristine tropical rainforest air of Amazonia: size-resolved measurements and modeling of atmospheric aerosol composition and CCN activity. Atmos. Chem. Phys. 9 (19), 7551-7575.

Gysel, M., McFiggans, G. B., Coe, H., 2009. Inversion of tandem differential mobility analyser (TDMA) measurements. J. Aerosol Sci. 40 (2), 134-151. 
Hallquist, M., Wenger, J. C., Baltensperger, U., Rudich, Y., Simpson, D., Claeys, M., Dommen, J., Donahue, N. M., George, C., Goldstein, A. H., Hamilton, J. F., Herrmann, H., Hoffmann, T., Iinuma, Y., Jang, M., Jenkin, M. E., Jimenez, J. L., Kiendler-Scharr, A., Maenhaut, W., McFiggans, G., Mentel, T. F., Monod, A., Prévôt, A. S. H., Seinfeld, J. H., Surratt, J. D., Szmigielski, R., Wildt, J., 2009. The formation, properties and impact of secondary organic aerosol: current and emerging issues. Atmos. Chem. Phys. 9 (14), 5155.

Hays, M. D., Geron, C. D., Linna, K. J., Smith, N. D., Schauer, J. J., 2002. Speciation of Gas-Phase and Fine Particle Emissions from Burning of Foliar Fuels. Environ. Sci. Technol. 36 (11), 2281-2295.

Herich, H., Hueglin, C., Buchmann, B., 2011. A 2.5 year's source apportionment study of black carbon from wood burning and fossil fuel combustion at urban and rural sites in Switzerland. Atmos. Meas. Tech. 4, 1409-1420.

Heringa, M. F., DeCarlo, P. F., Chirico, R., Tritscher, T., Dommen, J., Weingartner, E., Richter, R., Wehrle, G., Prévôt, A. S. H., Baltensperger, U., 2011. Investigations of primary and secondary particulate matter of different wood combustion appliances with a high-resolution time-of-flight aerosol mass spectrometer. Atmos. Chem. Phys. 11, 5945-5957.

Jimenez, J. L., Canagaratna, M. R., Donahue, N. M., Prevot, A. S. H., Zhang, Q., Kroll, J. H., DeCarlo, P. F., Allan, J. D., Coe, H., Ng, N. L., Aiken, A. C., Docherty, K. D., Ulbrich, I. M., Grieshop, A. P., Robinson, A. L., Duplissy, J., Smith, J. D., R.Wilson, K., Lanz, V. A., Hueglin, C., Sun, Y. L., Tian, J., Laaksonen, A., Raatikainen, T., Rautiainen, J., Vaattovaara, P., Ehn, M., Kulmala, M., Tomlinson, J. M., Collins, D. R., Cubison, M. J., Dunlea, E. J., Huffman, J. A., Onasch, T. B., Alfarra, M. R., I.Williams, P., Bower, K., Kondo, Y., Schneider, J., Drewnick, F., Borrmann, S., Weimer, S., Demerjian, K., Salcedo, D., Cottrell, L., Griffin, R., Takami, A., Miyoshi, T., Hatakeyama, S., Shimono, A., Sun, J., Zhang, Y. M., Dzepina, K., Kimmel, J. R., Sueper, D., Jayne, J. T., Herndon, S. C., Trimborn, A. M., Williams, L. R., C.Wood, E., Kolb, C. E., Baltensperger, U., R.Worsnop, D., 2009. Evolution of Organic Aerosols in the Atmosphere. Science 326 (5959), 1525-529.

Jurányi, Z., Gysel, M., Duplissy, J., Weingartner, E., Tritscher, T., Dommen, J., Henning, S., Ziese, M., Kiselev, A., Stratmann, F., George, I., 
Baltensperger, U., 2009. Influence of gas-to-particle partitioning on the hygroscopic and droplet activation behaviour of $\alpha$-pinene secondary organic aerosol. Phys. Chem. Chem. Phys. 11 (36), 8091-8097.

Kaufman, Y. J., Hobbs, P. V., Kirchhoff, V. W. J. H., Artaxo, P., Remer, L. A., Holben, B. N., King, M. D., Ward, D. E., Prins, E. M., Longo, K. M., Mattos, L. F., Nobre, C. A., Spinhirne, J. D., Ji, Q., Thompson, A. M., Gleason, J. F., Christopher, S. A., Tsay, S.-C., 1998. Smoke, Clouds, and Radiation-Brazil (SCAR-B) experiment. J. Geophys. Res. 103 (D24), 31783-31808.

Lanz, V., Alfarra, M., Baltensperger, U., Buchmann, B., Hueglin, C., Szidat, S., Wehrli, M., Wacker, L., Weimer, S., Caseiro, A., Puxbaum, H., Prevot, A., 2008. Source attribution of submicron organic aerosols during wintertime inversions by advanced factor analysis of aerosol mass spectra. Environ. Sci. Technol. 42, 214-220.

Lanz, V. A., Prévôt, A. S. H., Alfarra, M. R., Mohr, C., DeCarlo, P. F., Gianini, M. F. D., Hueglin, C., Schneider, J., Favez, O., D'Anna, B., George, C., Baltensperger, U., 2010. Characterization of aerosol chemical composition by aerosol mass spectrometry in Central Europe: an overview. Atmos. Chem. Phys. 10, 10453-10471.

Lee, Y. S., Collins, D. R., Li, R., Bowman, K. P., Feingold, G., 2006. Expected impact of an aged biomass burning aerosol on cloud condensation nuclei and cloud droplet concentrations. J. Geophys. Res 111, D22204.

Lohmann, U., Hoose, C., 2009. Sensitivity studies of different aerosol indirect effects in mixed-phase clouds. Atmos. Chem. Phys. 9, 8917-8934.

Massoli, P., Lambe, A. T., Ahern, A. T., Williams, L. R., Ehn, M., Mikkil, J., Canagaratna, M. R., Brune, W. H., Onasch, T. B., Jayne, J. T., Petj, T., Kulmala, M., Laaksonen, A., Kolb, C. E., Davidovits, P., Worsnop, D. R., 2010. Relationship between aerosol oxidation level and hygroscopic properties of laboratory generated secondary organic aerosol (SOA) particles. Geophys. Res. Lett 37, L24801.

Paulsen, D., Dommen, J., Kalberer, M., Prevot, A. S. H., Richter, R., Sax, M., Steinbacher, M., Weingartner, E., Baltensperger, U., 2005. Secondary 
organic aerosol formation by irradiation of 1,3,5-trimethylbenzene-NOx$\mathrm{H} 2 \mathrm{O}$ in a new reaction chamber for atmospheric chemistry and physics. Environ. Sci. Technol. 39 (8), 2668-2678.

Petters, M. D., Carrico, C. M., Kreidenweis, S. M., Prenni, A. J., DeMott, P. J., Collett, J. L., Moosmüller, H., 2009a. Cloud condensation nucleation activity of biomass burning aerosol. J. Geophys. Res. 114, D22205.

Petters, M. D., Kreidenweis, S. M., 2007. A single parameter representation of hygroscopic growth and cloud condensation nucleus activity. Atmos. Chem. Phys. 7, 1961-1971.

Petters, M. D., Wex, H., Carrico, C. M., Hallbauer, E., Massling, A., McMeeking, G. R., Poulain, L., Wu, Z., Kreidenweis, S. M., Stratmann, F., 2009b. Towards closing the gap between hygroscopic growth and activation for secondary organic aerosol - Part 2: Theoretical approaches. Atmos. Chem. Phys. 9, 3999-4009.

Pósfai, M., Simonics, R., Li, J., Hobbs, P. V., Buseck, P. R., 2003. Individual aerosol particles from biomass burning in southern Africa: 1. Compositions and size distributions of carbonaceous particles. J. Geophys. Res. 108(D13), 8483.

Reid, J., Hobbs, P., 1998. Physical and optical properties of young smoke from individual biomass fires in Brazil. J. Geophys. Res. 103 (D24), 3201332030 .

Reid, J. S., Koppmann, R., Eck, T. F., Eleuterio, D. P., 2005. A review of biomass burning emissions part ii: intensive physical properties of biomass burning particles. Atmos. Chem. Phys. 5, 799-825.

Reutter, P., Su, H., Trentmann, J., Simmel, M., Rose, D., Gunthe, S. S., Wernli, H., Andreae, M. O., and Pöschl, U., 2009. Aerosol- and updraftlimited regimes of cloud droplet formation: influence of particle number, size and hygroscopicity on the activation of cloud condensation nuclei (CCN). Atmos. Chem. Phys., 9, 7067-7080.

Roberts, G. C., Nenes, A., 2005. A Continuous-Flow Streamwise ThermalGradient CCN Chamber for Atmospheric Measurements. Aerosol Sci. Technol. 39 (3), 206-221. 
Rose, D., Gunthe, S. S., Mikhailov, E., Frank, G. P., Dusek, U., Andreae, M. O., and Pöschl, U.: Calibration and measurement uncertainties of a continuous-flow cloud condensation nuclei counter (DMT-CCNC): CCN activation of ammonium sulfate and sodium chloride aerosol particles in theory and experiment, Atmos. Chem. Phys., 8, 1153-1179, 2008.

Sandradewi, J., Prévôt, A., Szidat, S., Perron, N., Alfarra, M., Lanz, V., Weingartner, E., Baltensperger, U., 2008. Using aerosol light absorption measurements for the quantitative determination of wood burning and traffic emission contributions to particulate matter. Environ. Sci. Technol. 42 (9), 3316-3323.

Stokes, R. H., Robinson, R. A., 1966. Interactions in aqueous nonelectrolyte solutions. I. Solute-solvent equilibria. J. Phys. Chem. 70 (7), 2126-2131.

Szidat, S., Prévôt, A. S. H., Sandradewi, J., Alfarra, M. R., Synal, H.-A., Wacker, L., Baltensperger, U., 2007. Dominant impact of residential wood burning on particulate matter in Alpine valleys during winter. Geophys. Res. Lett 34, L05820.

Topping, D. O., McFiggans, G. B., Coe, H., 2005. A curved multi-component aerosol hygroscopicity model framework: Part 1 - Inorganic compounds. Atmos. Chem. Phys. 5 (5), 1205-1222.

Tritscher, T., Dommen, J., DeCarlo, P. F., Barmet, P. B., Praplan, A. P., Weingartner, E., Gysel, M., Prévôt, A. S. H., Riipinen, I., Donahue, N. M., Baltensperger, U., 2011a. Volatility and hygroscopicity of aging secondary organic aerosol in a smog chamber. Atmos. Chem. Phys. Discuss. 11, 74237467 .

Tritscher, T., Jurányi, Z., Martin, M., Chirico, R., Gysel, M., Heringa, M. F., DeCarlo, P. F., Sierau, B., Prévôt, A. S. H., Weingartner, E., Baltensperger, U., 2011b. Changes of hygroscopicity and morphology during aging of diesel soot. Environ. Res. Lett. 6, 034026.

Vestin, A., Rissler, J., Swietlicki, E., Frank, G. P., Andreae, M. O., 2007. Cloud-nucleating properties of the Amazonian biomass burning aerosol: Cloud condensation nuclei measurements and modeling. J. Geophys. Res 112, D14201. 
Weingartner, E., Baltensperger, U., Burtscher, H., 1995. Growth and structural change of combustion aerosols at high relative humidity. Environ. Sci. Technol. 29 (12), 2982-2986.

Weingartner, E., Burtscher, H., Baltensperger, U., 1997. Hygroscopic properties of carbon and diesel soot particles. Atmos. Env. 31 (15), 2311-2327.

Wotawa, G., Trainer, M., 2000. The Influence of Canadian Forest Fires on Pollutant Concentrations in the United States. Science 288 (5464), 324328.

Zhang, R., Khalizov, A. F., Pagels, J., Zhang, D., Xue, H., McMurry, P., 2008. Variability in morphology, hygroscopicity, and optical properties of soot aerosols during atmospheric processing. Proc. Natl. Acad. Sci. 105 (30), 10291-10296.

Zhang, K., O’Donnell,D., Kazil, J., Stier, P., Kinne, S., Lohmann, U., Ferrachat, S., Croft, B., Quaas, J., Wan, H., Rast, S. and Feichter, J., 2012. The global aerosol-climate model ECHAM-HAM, version 2: sensitivity to improvements in process representations. Atmos. Chem. Phys. Discuss., $12,7545-7615$.

Zuberi, B., Johnson, K. S., Aleks, G. K., Molina, L. T., Molina, M. J., Laskin, A., 2005. Hydrophilic properties of aged soot. Geophys. Res. Lett. 32, L01807. 